\title{
Assessment the Efficiency of Solid Waste Management Tayba Al Hasanab Landfill, Khartoum Municipality Sudan
}

\author{
Safa Abdel Aziz Mohammed Yadi* \\ Department of Environmental technology, Omdurman Ahlia University, Sudan
}

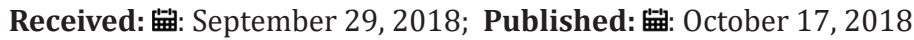

*Corresponding author: Safa Abdel Aziz Mohammed Yadi, Lecturer, Department of Environmental technology, Faculty of Environmental Sciences, Omdurman Ahlia University, Sudan

\begin{abstract}
Management of solid waste all over the world is one of the most important priorities to protecting communities' health, as well as, the urban environment. So, improper solid waste management, causes serious health hazard, spreading of disease, injuries, air and water pollution. This Paper is an attempt to assess the efficiency of solid waste management in Tayba Al Hasanab landfill and to highlight health and environmental impacts expected from inefficient solid waste management in the study area. This study has adopted descriptive methods. Primary data were collected through frequent field visits, photos documentation, personal observations and interviewing sites head manager. While Secondary data were collected through reviewing the available literature. Inefficient solid waste management can attributed to irrelevant location of this dumping site. This has resulted in nuisance and health hazards for the people living nearby. However, inefficient solid wastes are resulted from, inaccessible road during the rainy season has enforced the vehicle's drivers to dump their wastes outside the landfill, poor funding, steady increase in the generated wastes due to vast population growth and poor community awareness. Moreover, workers are not wear personal protective equipment. One can conclude that inefficient solid wastes management in the study area is due to anthropogenic and man-made factors. The following recommendations can be drawn: Tayba Al Hassanab landfill should be rehabilitated and redesigned to comply with the recommended standards as well as raising awareness of workers with occupational health, safety and environment measures.
\end{abstract}

Keywords: Landfill; Solid Waste Management; Inefficient and Anthropogenic And Man-Made Factors

\section{Introduction}

Khartoum municipality as one of the seven municipalities of Khartoum states, faces influx of displaced people as well refugees, which has resulted in tremendous increase in population. This increase lead to an increase in the production of more solid wastes as well [4]. Municipal Solid Waste management represents one of the headache which generally affect public health and environment, as result of inefficient solid waste management practices especially collection, processing and disposing in this municipality [1]. Moreover, wastes in such places are dumped without any management, leading negative environmental impacts, which are manifested in air and water pollution as well as land contamination, so consequently these wastes, will affect human health and degrade their environment [2]. Our houses are one of the major sources which discard domestic solid waste materials daily, these garbage and wastes are, food residues, glass, vegetables and fruits, wood, papers, minerals and plastic. Therefore, segregation and transporting of these material to the final disposal site are important for the protecting human health and environment [3].

\section{Background to the Problem of Inefficient Waste Man-} agement Practices

Solid waste management is a growing problem in Khartoum city, this is because these wastes are randomly disposed, and as such they one of the main sources of environmental pollution. Wastes are used to be disposed by traditional ways such as burning and uncovered dunghills. These ways lead to many environmental problems and distort the city scenes. Moreover, bad smell emission and smoke from burning threatens lives of human, animal and plant as well as, making it the deterioration livelihoods of inhabitants [4]. Solid waste management practices in Sudan are inefficient, due to increase in waste generation especially in Khartoum city. There are different factors which contributing to increasing wastes generation in Khartoum, these are changes in food habit and widespread use of disposable containers and packages. Moreover, improper collection of these wastes and dumping it, in street and drains channels, lead to great a health threat. Also, they serve as breeding sites 
for insect and rodent vectors which they lead to spread of different diseases [1].

\section{Objectives}

a) To assess the efficiency of solid waste management at Tayba Al Hassanab landfill.

b) To identify health and environmental hazards expected from inefficient solid waste management in the study area.

\section{Material and Methods}

\section{Description of the Study Area}

This is descriptive study was conducted in Tayba landfill, Khartoum locality. Khartoum executive capital of Sudan. The total population state at 2018 was recorded as being 8.0 million, the city of Khartoum (latitudes 15 to $16^{\circ} \mathrm{N}$ longitudes 31.5 to $34^{\circ} \mathrm{E}$ ). The weather is rainy in the summer, and cold and dry in the winter, temperature ranges between in summer ranges from 25 to $40{ }^{\circ} \mathrm{C}$ from April to June, and from 20 to $35^{\circ} \mathrm{C}$ in the months of July to October. Situated at the junction between the Blue and the White Nile together with Omdurman to the west and Khartoum North to the north, form Khartoum Sudan dominating urban centers [4]. Tayba landfill was established at 2008, located in Jabel Awlia locality, East the residential area of Tayba Al Hasanab, far about 4 $\mathrm{km}$. It is bordered eastward by Soba agricultural project and South the poultry farms [5]. (Figure 1)

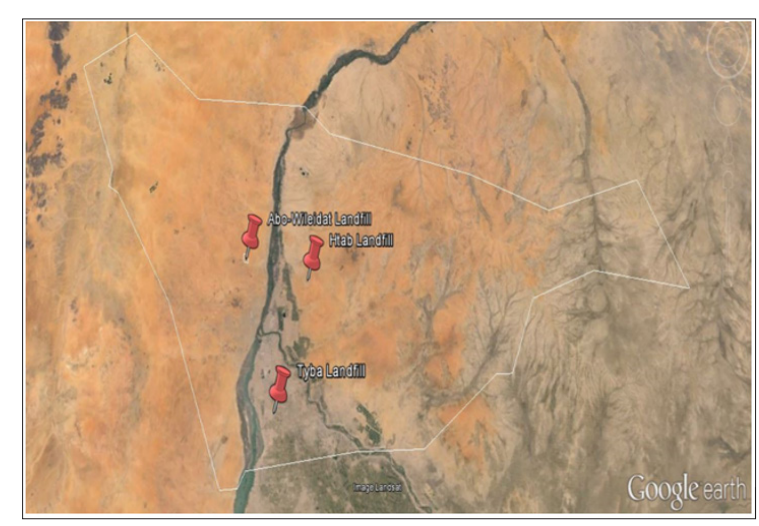

Figure 1: Location of landfill. Source: Higher Council for Environment, Urban and Rural Promotion.

\section{Methods}

Different tools had been adopted to satisfy the above-mentioned objectives, Data were collected from primary and secondary sources. i.e. Site visit, photos documentation, personal observations, interview with head manager of the site, whereas Secondary data was collected from the Higher Council for Environment, Urban and Rural Promotion, previous study and textbooks.

\section{Result and Discussion}

\section{General Overview}

Tayba Al Hasanab landfill is operated by Khartoum Municipality, and the Higher Council for Environment, Urban and Rural Promotion. Total area of the landfill is 40 feddan [5]. This site receives the waste from different sources, which are Jabel Awlia locality and Khartoum municipalities. Moreover, the solid waste which received from jabel Awlia locality dispose directly to the area without compaction, but the other wastes from different areas compacted at Khartoum transfer station, then dispose to the site [5]. Solid wastes dumped at this landfill can be classified into domestic solid waste which represent the bulk, slaughtering waste and medical waste in small quantities. According to the Higher Council for Environment, Urban and Rural Promotion, the statistical analysis has shown that, the amount of waste transferred is approximately 2115- 26000 tones / day, with an average 270-290 trip per years [5].

\section{Assessment of Solid Waste Management at Tayba Al Hasanab Landfill}

Impact of the Location of Tayba Landfill: The survey indicates that, the location of Tayba land fill is unstable, because it is negatively affecting nearby settlements and environment. This landfill is found to be pollute the soil, water and air. Besides that, wind can transfer plastic bags from wastes to their surrounding areas effect on a landscape. Bad odor released from waste causing many health problems, such as irritation of nose, of the residence. The prevailing environmental conditions at this landfill, provide suitable habitat for breeding site of flies, mosquitoes and rats. this lead to spread disease to the resident, also leachate polluting groundwater and water table make it unsuitable for human uses [6]. During the rainy season road leading to the landfill is inaccessible. consequently, the vehicle's drivers are enforced to dump their wastes outside the landfill. On the other hand, Trucks used in landfills are noisy, and therefore disturb the neighboring residence in addition to that these vehicles are cause airborne dust particles [6]

Segregation of Solid Waste at the Landfill: Generally, segregation begins during the unloading of Lorries, randomly by scavengers. Scavengers come to the landfill daily searching for plastics bottles (Figure 2). They sell these items to recycling companies [6]. The age profile of Scavengers ranges from children to adults from both sexes. Since, those scavengers are neither use gloves, masks nor boots, therefore they are subjected to accidents from broken glass. Therefore, injures from dispose syringes which are found in the remained wastes, this may subject them to infectious diseases such as hepatitis and HIV (Figures 3a \& 3b). These can be attributed to poor awareness among them [6].

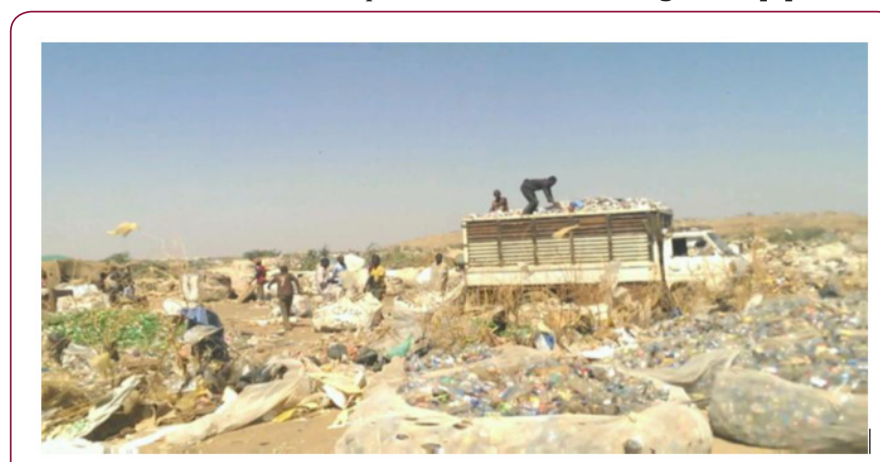

Figure 2: Picking, Plastic bottles and Beverage can for recycling. 


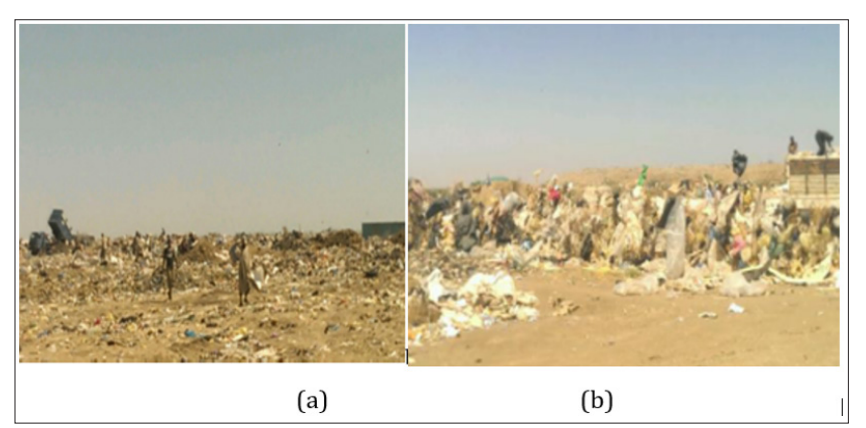

Figure 3: (a) \& (b) Segregation without using personal protective equipment.

Treatment and Disposal of Solid Waste at the Study Area: There is no any treatment method currently adopted for managing the solid wastes. Flowing their compacting, the wastes are then transported by trucks, to the landfill. Solid wastes treatment in this landfill is in complete due to the fact that there is insufficient soil to cover these wastes [5].

\section{Constraints Facing the Landfill}

This survey indicates that the existing solid waste management system in Khartoum municipality are insufficient with special regards to, especially at Tayba Al Hasanab landfill due to the following constraints (Figure 4)

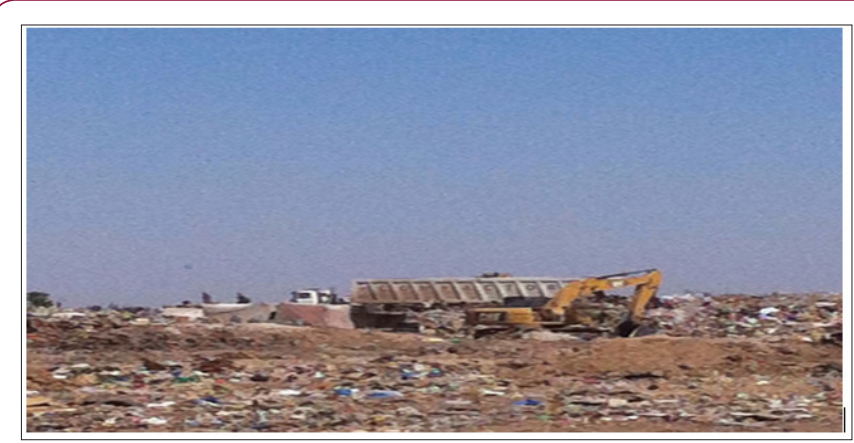

Figure 4: Solid waste transportation and disposal at Tayba Al Hasanab.

a. Insufficient soil to cover wastes.

b. There is neither electricity nor health care services at the site.

c. Only one office is existing.

d. Insufficient number of vehicles to transfer wastes to the landfill.

e. There is no health officer to control the breeding of mosquitoes, insects and rats.

f. The presence of the informal settlements of scavengers inside the landfill, this hinders the process of sorting out of the waste.

g. Tayba landfill site is neighboring the residential areas.

h. There is no regular collection, treatment and disposal.

\section{Impacts of Inefficient Solid Waste Management}

Interviewing the head manager has revealed that there is only on labour is assigned for each vehicle to collect and dispose wastes. So, this reflects that number of vehicles as well as labour is insufficient to perform the task fully. Moreover, there is no sanitary control sanitary over Tayba Al Hasanab landfill (Figure 5).

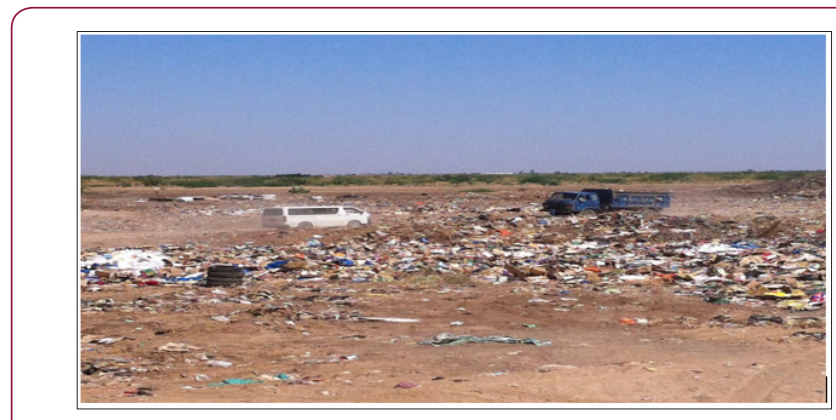

Figure 5: It can be noticed that, the organic wastes, can become a suitable breeding site for flies, mosquitoes and rats, and may create vector for many diseases [6].

\section{According to Site Visits and Observations Revealed the Following:}

a. Solid wastes are poorly dumped, there is no site preparation, and its lack type of waste management and treatment.

b. Tayba landfill lies closely to the residential area of Tayba Al Hasanab.

c. Wastes are not covered daily with soil; therefore, they cause nuisance and health hazards for the people living nearby.

d. There is no gas and leachate management, This may lead to the contamination of the ground water in the study area, which is main source of potable water to the people living in the study area.

e. The site is unfenced and therefore there is no control over the scavengers.

f. Methane which is expected to be produced from the fermentation of food remains will increase the hazards of spontaneous fires.

g. It can be noticed that, the organic wastes, can become a suitable breeding site for flies, mosquitoes and rats, and may create vector for many diseases [6].

\section{Conclusion \& Recommendations}

\section{Conclusion}

Solid waste management in Tayba Al Hassanab landfill is inefficient, due to the following factors:

a) Inaccessible road during the rainy season.

b) Poor funding.

c) Rapid increase in waste generation due to increase their population growth, and improper waste management practices. 
d) Workers they are not were personal protective equipment.

\section{Recommendations}

a) Development of comprehensive solid waste management plan and ensuring its proper implementation.

b) Enough budgets should be allotted to ensure efficient treatment and management.

c) Raise public awareness of the community in schools and universities as well as using the media such as TV, radio, What's App and Facebook.

d) Tayba Al Hassanab landfill should be rehabilitated and redesigned to comply with the recommended standards e.g. With regard fencing, managerial improvement aspects.

e) To recruit more health and safety officers on the site to monitor the health and safety of labours and raise their awareness and to reduce hazards associated with inefficient solid waste management processes.

\section{ISSN: 2574-1241}

DOI: 10.26717/BJSTR.2018.10.001912

Safa Abdel Aziz Mohammed Yadi. Biomed J Sci \& Tech Res

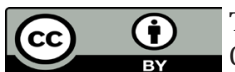

This work is licensed under Creative Commons Attribution 4.0 License

Submission Link: https://biomedres.us/submit-manuscript.php f) Fencing of the site is a prerequisite to keep out scavengers and animals.

\section{References}

1. Abubaker BM A, Alhadi M, Magzoub A, Mohmmed A, Hussein G, et al. (2014) Investigating the Solid Waste Management Problems in Urban Area, Sudan, International Journal of Engineering Research \& Technology. (IJERT) 3(6): 2278-0181.

2. Birhanu Y, Berisa G (2015) Assessment of Solid Waste Management Practices and the Role of Public Participation in Jigjiga Town, Somali Regional State, Ethiopia, International Journal of Environmental Protection and Policy 3(5): 153-168.

3. Elbaroudi NOM, Ahmed SEM, Adam EEA (2015) Solid Wastes Management In Urban Areas: The Case of Khartoum State, Sudan, journal of Pinnacle Engineering \& Technology 3(2): 2360-9508.

4. Ali FAH (2017) Evaluation of solid waste management in Khartoum state and selection of landfill sites, Using GIS technique, Sudan university of science and technology.

5. (2018) Higher Council for Environment, Urban and Rural Promotion, Khartoum Sudan. Personal communication.

6. (2018) Field survey conducted by the author.

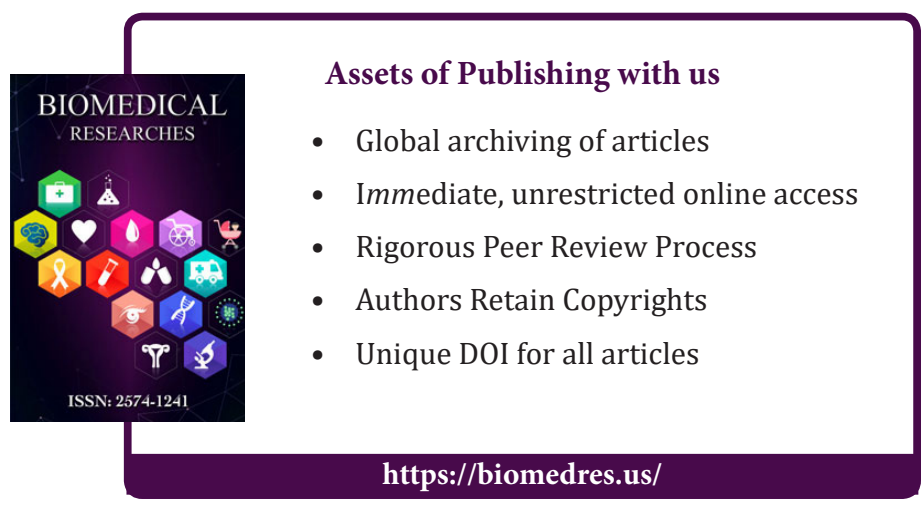

